\title{
Dari Krisis Ruang Publik ke Kemitraan Intersektoral: Studi Kasus di RPTRA Kalijodo, Jakarta
}

\author{
Rakhmat Hidayat ${ }^{1}$, Ayuningtyas Suciani Utari $^{2}$ \\ [Universitas Negeri Jakarta, ${ }^{1}$ hidayat@ unj.ac.id, ${ }^{2}$ ayuningtyassuciani@live.com ]
}

Diterima: 06/09/2018

Direview: $12 / 11 / 2018$

Diterbitkan: 31/12/2018

Hak Cipta @ 2018 oleh Penulis (dkk) dan Jurnal Sosial Humaniora (JSH)

*This work is licensed under the Creative

Commons Attribution International License (CC

BY 4.0).

http://creativecommons.org/licenses/by/4.0/ Open Access

\section{Subject Area : Social and Politics (Sosial dan Politik)}

\section{Abstract}

This article discusses about the partnership between stakeholders in managing Child-Friendly Integrated Public Space (RPTRA) in Kalijodo, West Jakarta. Researchers use the Child-Friendy Integrated Public Space concepts, stakeholder concepts, and partnership stakeholder concepts. This article will explain about the roles and relations of stakeholders in managing RPTRA Kalijodo, also the implications of the relation between stakeholders in managing that RPTRA. Partnerships between stakeholders that involved in RPTRA Kalijodo include the division of roles, cooperation, and collaboration between the local government and the surrounding society as an effort to manage the RPTRA Kalijodo. The existence of that relation can be a partnership between stakeholders that involved, so the management of the RPTRA can run optimally and RPTRA Kalijodo can be utilized by the society.

Keywords: stakeholder, partnership, managing, child friendly integrated public space, relation

\section{Pendahuluan}

Permasalahan di Ibu kota Jakarta salah satunya berakar pada persoalan kependudukan, terutama masalah 'ledakan' penduduk yang hingga kini belum terkendali secara efektif. Berdasarkan data terakhir tahun 2017 dari Katalog Badan Pusat Statistik (BPS) Provinsi DKI Jakarta diketahui bahwa total kepadatan penduduk Jakarta pada tahun 2016 berjumlah $15.517,38$ jiwa per $\mathrm{km}^{2}$. Kota Administrasi Jakarta Barat menjadi wilayah dengan tingkat kepadatan penduduk tertinggi di DKI Jakarta yaitu sebesar 19.269,20 jiwa per $\mathrm{km}^{2}$. Hal tersebut dapat digambarkan melalui tabel 1.

Tabel 1

Distribusi Kepadatan Penduduk Menurut Kabupaten/Kota di DKI Jakarta Tahun 2016

\begin{tabular}{|c|c|c|}
\hline Kabupaten/Kota & Persentase Penduduk & Kepadatan Penduduk per km² $^{2}$ \\
\hline$(1)$ & $(2)$ & (3) \\
\hline Kepulauan Seribu & 0,23 & 714,48 \\
\hline Jakarta Selatan & 21,47 & 20,67 \\
\hline Jakarta Timur & 27,91 & 57,72 \\
\hline Jakarta Pusat & 8,93 & 68,23 \\
\hline Jakarta Barat & 24,92 & 69,20 \\
\hline Jakarta Utara & 17,17 & 12032,01 \\
\hline DKI Jakarta & 100,00 & 15517,38 \\
\hline
\end{tabular}

Ket. : Katalog Badan Pusat Statistik Provinsi DKI Jakarta (Jakarta dalam angka 2017) 
Implikasi dari adanya permasalahan kepadatan penduduk yang terjadi, berakibat pada munculnya masalah sosial lainnya. Kepadatan penduduk pada akhirnya akan mempersempit ruang gerak masyarakat yang bertempat tinggal di wilayah kota Jakarta terutama di wilayah Jakarta Barat. Ruang publik yang dapat digunakan sebagai tempat berinteraksi antar sesama masyarakat menjadi berkurang karena banyaknya lahan yang telah dibangun menjadi pemukiman penduduk dan gedung-gedung tinggi. Area bermain, ruang bebas untuk berolahraga, serta serta ruang publik yang dapat dimanfaatkan sebagai ruang edukasi oleh anakanak pun semakin minim. Padahal masyarakat khususnya anak-anak membutuhkan sebuah ruang yang dapat dimanfaatkan untuk berekspresi, bermain, dan berinteraksi satu sama lain. Kondisi ini menunjukkan bahwa masih adanya hak-hak anak yang belum terpenuhi terutama dalam mengakses ruang publik yang ramah bagi mereka khususnya di wilayah perkotaan yang padat penduduknya seperti Jakarta.

Sebagai suatu solusi dalam memberikan perlindungan dan pengembangan potensi anak sesuai dengan aspek legalitas hak anak yang mendasarinya, pemerintah melalui Kementerian Pemberdayaan Perempuan dan Perlindungan Anak Republik Indonesia mencanangkan kebijakan berupa program Kota Layak Anak (KLA). KLA merupakan kota yang mempunyai sistem pembangunan berbasis hak anak melalui pengintegrasian komitmen dan sumber daya pemerintah, masyarakat, dan dunia usaha yang terencana secara menyeluruh dan berkelanjutan dalam kebijakan, program, dan kegiatan untuk menjamin terpenuhinya hak dan perlindungan anak. KLA juga menjadi salah satu program stategis dalam Rencana Pembangunan Jangka Menengah Daerah (RPJMD) Provinsi DKI Jakarta tahun 2013 -2017 (Bappeda DKI Jakarta: 218). Berdasarkan Keputusan Menteri Negara Pemberdayaan Perempuan dan Perlindungan Anak Republik Indonesia Nomor 56 Tahun 2010 tentang Penunjukkan dan Penetapan 10 Provinsi untuk mengembangkan Kabupaten/Kota Layak Anak, Provinsi DKI Jakarta termasuk provinsi yang ditunjuk untuk mengembangkan KLA bersama 9 provinsi lainnya di Indonesia. Hal tersebut dapat dilihat dalam tabel 2.

Tabel 2

10 Provinsi Pilot Project Pengembangan Kabupaten/Kota Layak Anak

\begin{tabular}{|c|l|}
\hline No. & \multicolumn{1}{c|}{ Nama Provinsi } \\
\hline 1. & Daerah Khusus Ibu kota Jakarta \\
\hline 2. & Banten \\
\hline 3. & Jawa Barat \\
\hline 4. & Jawa Tengah \\
\hline 5. & Jawa Timur \\
\hline 6. & Sumatera Utara \\
\hline 7. & Bali \\
\hline 8. & Kepulauan Riau \\
\hline 9. & Kalimantan Timur \\
\hline 10. & Daerah Istimewa Yogyakarta \\
\hline
\end{tabular}

Sumber: Keputusan Menteri Pemberdayaan Perempuan dan Perlindungan Anak RI No. 56 Tahun 2010

Berdasarkan Keputusan Menteri Negara interaksi publik yang memadai bagi anak. Ruang Pemberdayaan Perempuan dan Perlindungan Anak Republik Indonesia Nomor 56 Tahun 2010; salah satu indikator dari KLA adalah tersedianya ruang Publik Terpadu Ramah Anak (selanjutnya disingkat RPTRA) merupakan wujud dari pengembangan kebijakan KLA yang telah dilakukan oleh 
Pemerintah Provinsi DKI Jakarta. Hal ini tertuang dalam Peraturan Gubernur Provinsi DKI Jakarta No. 40 Tahun 2016 tentang Pedoman Pengelolaan Ruang Publik Terpadu Ramah Anak yang menegaskan bahwa RPTRA adalah ruang terbuka yang memadukan kegiatan dan aktivitas warga dengan mengimplementasikan sepuluh program pokok Pemberdayaan dan Kesejahteraan Keluarga (PKK) untuk mengintegrasikannya dengan program KLA.

Adanya RPTRA menjadi salah satu komitmen dari Pemerintah Provinsi DKI Jakarta untuk menjamin terpenuhinya hak anak agar anak dapat hidup, tumbuh, berkembang, dan berpartisipasi secara optimal sesuai dengan harkat dan martabatnya serta sebagai upaya untuk mendukung DKI Jakarta menjadi Kota Layak Anak. Kajian penelitian mengenai RPTRA tentunya menjadi hal yang perlu untuk diteliti karena program RPTRA sendiri merupakan suatu inovasi baru dalam konsep penyediaan ruang publik ramah anak di Indonesia dan pertama kali diterapkan di Provinsi DKI Jakarta. Adanya program RPTRA di Jakarta dapat menjadi contoh atau role model bagi kota lain dalam penyediaan ruang publik bagi masyarakat kota khususnya anak-anak. Selain itu, RPTRA yang berada di tengah kepadatan penduduk dan pembangunan ibu kota Jakarta dapat menjadi lokasi yang tepat untuk dijadikan referensi tentang bagaimana sebuah lingkungan yang memiliki keterbatasan area dapat tetap menyediakan ruang untuk memenuhi kebutuhan anak.

Dibangunnya RPTRA di wilayah Jakarta menjadi suatu upaya yang bertujuan agar kota Jakarta menjadi salah satu kota yang layak bagi anak-anak. Untuk mewujudkan kota yang layak anak tersebut, tentunya juga dibutuhkan komitmen dan peran dari stakeholder yang terlibat dalam hal ini adalah pihak pemerintah setempat dan masyarakat sekitar yang saling bersinergi dan terkoordinir secara menyeluruh. Dengan adanya keterlibatan dan peran yang dilakukan oleh stakeholder yang terlibat, maka RPTRA yang ada dapat terkelola dengan baik sehingga program dan kegiatan yang berlangsung dapat menjadi salah satu pendorong untuk menjamin terpenuhinya hak dan perlindungan anak.

Fokus artikel ini adalah menekankan pada kemitraan pemangku kepentingan (stakeholder partnership) dalam pengelolaan RPTRA di Jakarta. Konsep kemitraan ini digunakan dalam diskursus pembangunan berkelanjutan (sustanaibility development) yang mengacu kepada berbagai masalah sosial dengan membangun dan meningkatkan kapasitas kolektif (collective capacity) dari berbagai pemangku kepentingan (MacDonald, 2016). Masalah sosial yang dimaksud dalam artikel ini adalah krisis ruang publik perkotaan khususnya di Jakarta. RPTRA dibangun sebagai salah satu solusi atas krisis tersebut. RPTRA sendiri memang program yang diinisiasi oleh pemerintah DKI Jakarta tetapi ada beberapa pemangku kepentingan yang terlibat dalam pengelolaannya. Sejalan dengan konsep kunci kemitraan pemangku kepentingan, artikel ini memusatkan kajiannya pada relasi sosial pemangku kepentingan tersebut. Dalam disiplin sosiologi, relasi sosial adalah salah satu konsep penting untuk menjelaskan individu dalam dunia sosial. Dengan demikian, artikel ini berkontribusi untuk memperkaya kajian kemitraan pemangku kepentingan dalam pembangunan kota yang berkelanjutan dengan menggunakan perspektif sosiologis.

\section{Metode Penelitian}

Dalam penelitian ini, peneliti menggunakan pendekatan kualitatif dengan metode studi kasus. Menurut Neuman, dalam penelitian kualitatif kita lebih 
mengandalkan prinsip-prinsip dari ilmu sosial interpretif atau kritis. Kita bicara dengan bahasa "kasus dan konteks" serta makna. Penekanannya adalah melakukan pemeriksaan terperinci dari berbagai kasus tertentu yang muncul secara alamiah dalam kehidupan sosial (Neuman, 2015: 188). Dalam konteks ini, penelitian lebih difokuskan dengan mengambil studi kasus di RPTRA Kalijodo yang terletak di Kelurahan Angke, Jakarta Barat. Waktu penelitian berlangsung dari bulan Januari hingga April 2018. Teknik pengumpulan data melalui observasi, studi pustaka, dan wawancara. Subjek dalam penelitian ini berjumlah 17 orang yang terdiri dari informan kunci dan informan tambahan. Informan kunci dalam penelitian ini yaitu Kepala Seksi Pemberdayaan Masyarakat dari Suku Dinas Pemberdayaan, Perlindungan Anak, dan Pengendalian Penduduk Kota Administrasi Jakarta Barat; 1 orang pembimbing kegiatan seni budaya di RPTRA Kalijodo dari Suku Dinas Pariwisata dan Kebudayaan Kota Administrasi Jakarta Barat; Lurah Angke Jakarta Barat; 6 orang Pasukan Pink pengelola harian RPTRA Kalijodo; serta 2 orang anggota Tim Penggerak Pemberdayaan Kesejahteraan Keluarga (PKK) Kelurahan Angke. Adapun informan tambahan dalam penelitian ini terdiri dari 1 orang konselor di Pos Pengaduan Kekerasan Perempuan dan Anak (P2KPA) RPTRA Kalijodo serta 5 orang masyarakat sekitar RPTRA Kalijodo.

\section{Hasil dan Pembahasan}

\section{A. Gambaran Umum RPTRA Kalijodo}

Kawasan Kalijodo yang dahulu terkenal sebagai red district dengan hiburan malam dan kegiatan illegal didalamnya telah bertransformasi. Pasca penertiban yang dilakukan pada Februari 2016, Pemerintah Provinsi DKI Jakarta melakukan revitalisasi dengan membangun dan mengembangkan kawasan tersebut menjadi RPTRA.
RPTRA Kalijodo menjadi salah satu hasil produk kebijakan dari rancangan tata ruang kota Jakarta dalam upaya pemenuhan kebutuhan ruang publik bagi masyarakat. Tepatnya pada 22 Februari 2017, Basuki Tjahaja Purnama selaku Gubernur DKI Jakarta kala itu meresmikan Kalijodo yang telah berubah wajah menjadi ruang publik terpadu yang ramah anak dan ruang terbuka hijau. Dirinya juga menjadikan RTH dan RPTRA yang terdapat di Kalijodo sebagai salah satu percontohan pembangunan ruang hijau di DKI Jakarta. Kawasan Kalijodo pun kini telah berubah menjadi lokasi rekreasi dan edukasi modern. Hadirnya RPTRA di kawasan Kalijodo merupakan hasil kerjasama antara Pemerintah Provinsi DKI Jakarta dan anak perusahaan Sinar Mas Land, yaitu PT Bumi Serpong Damai (BSD) Tbk melalui program Corporate Social Responsibility (CSR). Dalam prosesnya, kawasan Kalijodo pada akhirnya dapat diubah peruntukkannya menjadi sebuah ruang publik sebagai wadah interaksi masyarakat ibu kota. Pasca dibangun dan diresmikan, RPTRA Kalijodo menjadi aset milik Pemerintah Provinsi DKI Jakarta yang pengelolaannya dipantau langsung oleh Suku Dinas Pemberdayaan, Perlindungan Anak, dan Pengendalian Penduduk Kota Administrasi Jakarta Barat dengan melibatkan Satuan Kerja Perangkat Daerah (SKPD) lainnya yang terkait dan juga masyarakat sekitar.

\section{Gambar 1}

Ruang Publik Terpadu Ramah Anak Kalijodo

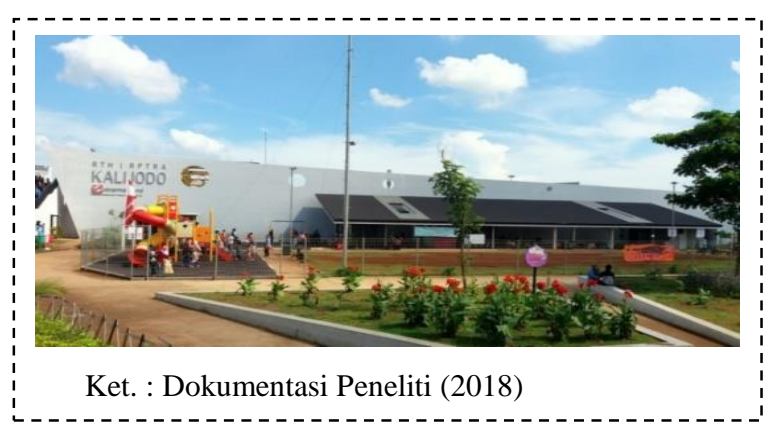


RPTRA Kalijodo menjadi suatu ruang publik yang dapat dimanfaatkan fungsinya oleh masyarakat mulai dari anak-anak, dewasa, lanjut usia (lansia), serta penyandang disabilitas. Di dalam RPTRA Kalijodo juga terdapat sarana untuk menunjang kebutuhan tumbuh kembang dan pembentukan karakter anak baik secara fisik, sosial, ataupun emosional. Hal ini dapat dilihat dari adanya fasilitas dan juga sarana yang telah terstandar dan aman bagi pengunjung, khususnya anak-anak di RPTRA Kalijodo. Area RPTRA juga menjadi tempat yang bebas dari asap rokok, sehingga ruang publik tersebut menjadi sebuah ruang yang ramah bagi anak-anak.

Gambar 2

Fasilitas di RPTRA Kalijodo

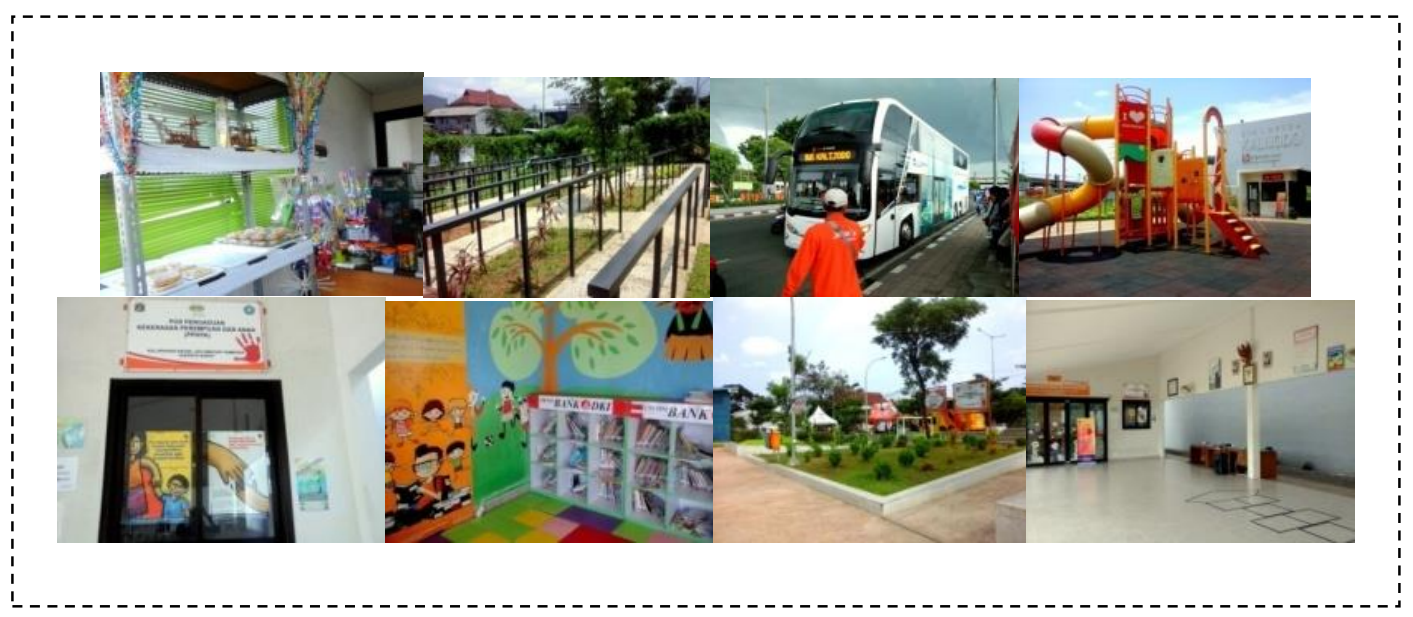

Ket.: Dokumentasi Peneliti (2018)

RPTRA Kalijodo juga menjadi salah satu ruang terbuka publik yang didalamnya terdapat fasilitas baik untuk aktivitas di luar ruangan (outdoor) maupun di dalam ruangan (indoor). Fasilitas tersebut di antaranya adalah fasilitas bermain dan tumbuh kembang anak, ruang edukasi dan perpustakaan, PKK Grossmart, Pos Pengaduan Kekerasan Perempuan dan Anak (P2KPA), aula serbaguna sebagai sarana untuk kegiatan sosial masyarakat, serta fasilitas pendukung lainnya seperti, jalur

\section{B. Relasi dan Kemitraan: Transformasi Kapasitas Kolektif}

Dalam pengelolaan RPTRA Kalijodo, pihak stakeholder yang terdiri dari pihak pemerintah setempat yang terkait dan masyarakat sekitar saling bekerjasama satu sama lain dalam mengelola RPTRA tersebut. Untuk memberikan gambaran secara lebih jelas, peneliti membuat sebuah skema yang menjelaskan tentang relasi antar stakeholder yang refleksi, kolam gizi, dan area terbuka hijau. RPTRA Kalijodo biasanya selalu dikunjungi oleh masyarakat dari berbagai kalangan, mulai dari anak-anak, orang dewasa, hingga lansia. Selain menyajikan ruang publik bagi masyarakat, akses menuju lokasi ini pun dapat dengan mudah dijangkau oleh masyarakat karena didukung oleh moda transportasi City Tour Bus Jakarta atau bus tingkat wisata yang dapat dinikmati secara gratis oleh masyarakat dengan rute IRTI Monas-Kalijodo ataupun sebaliknya.

terlibat di RPTRA Kalijodo. Hal ini bertujuan untuk memberikan visualisasi agar mempermudah pembaca dalam melihat penelitian ini serta untuk menjelaskan mengenai relasi yang terbangun antar masing-masing stakeholder yang terlibat di RPTRA tersebut. Berikut adalah skema relasi antarstakeholder di RPTRA Kalijodo. 


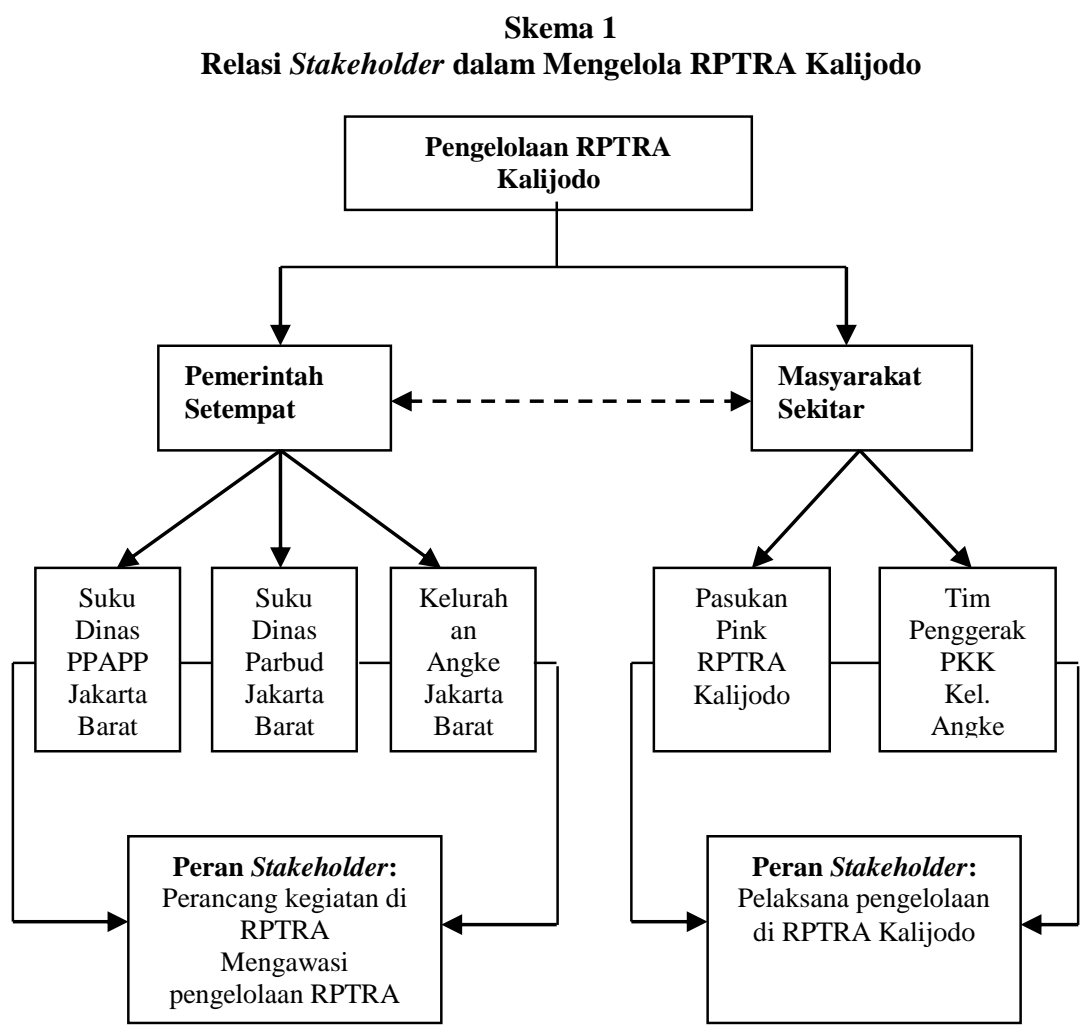

Ket.: Analisis Peneliti (2018)

RPTRA Kalijodo yang terletak di Kelurahan Angke, Jakarta Barat pada awalnya dapat dibangun karena adanya kerjasama antara Pemprov DKI Jakarta dan pihak swasta melalui program corporate social responsibility (CSR) PT Sinarmas Land, Tbk. Pasca dibangun dan diresmikan, RPTRA Kalijodo diharapkan dapat terus dimanfaatkan keberadaannya oleh masyarakat. Salah satu upaya yang dilakukan untuk mewujudkan hal tersebut adalah dengan menghidupkan RPTRA Kalijodo dengan beragam kegiatan yang diperuntukkan bagi masyarakat. Skema di atas menjelaskan bahwa untuk menyelenggarakan berbagai kegiatan di RPTRA Kalijodo, tentunya dibutuhkan peranan dari stakeholder yang terdiri dari Satuan Kerja Perangkat Daerah (SKPD) setempat yang terkait dan juga dukungan serta partisipasi dari masyarakat sekitar RPTRA Kalijodo yang berelasi dan saling bekerjasama untuk mengelola RPTRA tersebut.
Beberapa SKPD terkait berperan untuk merancang program dan kegiatan masyarakat di RPTRA serta mengawasi jalannya berbagai kegiatan yang berlangsung. SKPD yang terkait dalam hal ini adalah Suku Dinas Pemberdayaan, Perlindungan Anak, dan Pengendalian Penduduk (PPAPP) Jakarta Barat, Suku Dinas Pariwisata dan Kebudayaan Jakarta Barat, dan Kelurahan Angke. Sedangkan peranan lainnya juga dilakukan oleh masyarakat sekitar. Masyarakat sekitar melalui Tim Penggerak PKK Kelurahan Angke berperan untuk mengintegrasikan kegiatan-kegiatan PKK di dalam RPTRA Kalijodo. Selain itu, Pasukan Pink Pengelola RPTRA Kalijodo pun berperan dalam melayani masyarakat atau pengunjung RPTRA, serta menjadwalkan dan memfasilitasi jalannya berbagai kegiatan yang diselenggarakan di RPTRA Kalijodo. Multi-stakeholder dalam hal ini adalah SKPD setempat yang terkait dan juga beberapa masyarakat. Multistakeholder ini kemudian secara sadar 
mentransformasikan kemampuan dan kapasitas kolektif yang dimiliki oleh masing-masing yang pada akhirnya akan menghasilkan suatu kondisi dimana RPTRA Kalijodo dapat terkelola dan dapat menjadi suatu sarana untuk memenuhi kebutuhan masyarakat khususnya kebutuhan anak dalam suatu ruang publik.

\section{B. Urgensi Kemitraan: Kapitalisasi dan Pertukaran Sumber Daya}

RPTRA yang telah dibangun di Jakarta, salah satunya RPTRA Kalijodo tentunya penting dikelola agar ruang publik tersebut dapat selalu terawat dan dapat menjadi suatu sarana yang dapat dimanfaatkan oleh masyarakat khususnya anak-anak. Salah satu cara yang dapat dilakukan adalah dengan melakukan kemitraan yang dalam konteks penelitian ini dilakukan antara pemerintah setempat dan juga masyarakat sekitar dalam mengelola RPTRA Kalijodo. Kemitraan dapat didefiniskan sebagai suatu bentuk kerja sama atas dasar kesepakatan dan rasa saling membutuhkan dalam rangka meningkatkan kapasitas dan kapabilitas di suatu bidang usaha tertentu atau tujuan tertentu sehingga memperoleh hasil yang lebih baik (Sulistyani, 2004:129). Apabila dikaitkan dengan penelitian ini, RPTRA Kalijodo yang telah ada tentunya penting untuk dikelola melalui kerja sama dan kemitraan yang dilakukan antara pemerintah setempat yang terkait dan juga masyarakat sekitar. Hal tersebut perlu dilakukan agar keberadaan dan fungsi dari RPTRA dapat terjaga dan dapat dimanfaatkan oleh masyarakat. Kemitraan yang dilakukan oleh pemerintah setempat yang terkait dan masyarakat sekitar RPTRA Kalijodo pada dasarnya penting dilakukan agar keberadaan RPTRA tidak disalahgunakan oleh pihak-pihak yang tidak bertanggungjawab.

Adanya kemitraan dalam pengelolaan RPTRA Kalijodo juga penting dilakukan supaya RPTRA tersebut dapat selalu dikontrol dan diawasi bersama oleh masing-masing pihak yang terlibat agar masyarakat khususnya anak-anak dapat merasa nyaman ketika berada di dalam RPTRA Kalijodo. Selain itu, adanya kemitraan yang dilakukan oleh pemerintah setempat dan masyarakat dapat mengkapitalisasi sumber daya yang dimiliki setiap pemangku kepentingan. Artinya, ada proses transfer dan pertukaran sumber daya dan kapasitas sehingga membuat RPTRA bisa dikelola dengan baik. RPTRA Kalijodo bisa dikatakan sebagai RPTRA model yang menjadi rujukan RPTRA lainnya. Semua pemangku kepentingan terlibat dan berpartisipasi dalam kegiatan pengelolaan RPTRA tersebut.

\section{Sinergi Pemangku Kepentingan: Akselerasi Ruang Publik}

RPTRA menjadi program Pemerintah Provinsi DKI Jakarta melalui pembangunan ruang publik yang dapat digunakan bersama oleh masyarakat. RPTRA tentunya tidak sekedar ruang publik yang dapat digunakan oleh masyarakat untuk saling berkumpul dan beraktivitas di dalamnya, namun secara terpadu juga menyediakan kegiatan-kegiatan di luar ruang yang ramah bagi anak-anak. RPTRA adalah contoh dari program dan langkah strategis yang telah dilakukan oleh Pemerintah Provinsi DKI Jakarta untuk memenuhi kebutuhan dan hak anak khususnya di wilayah Jakarta. Pemerintah pada dasarnya memang memiliki kewajiban untuk menyediakan ruang publik khususnya yang dapat digunakan oleh anak-anak untuk memenuhi kebutuhan dan hak-hak mereka seperti hak untuk belajar dan bermain, namun pemerintah tidak sepenuhnya dapat bekerja sendiri dan tentunya diperlukan dukungan serta kerjasama dari pihak pemangku kepentingan yang terkait lainnya dalam proses pemenuhan hak anak melalui program RPTRA ini. Freeman (Ackerman \& Eden, 
2010) mengemukakan definisinya mengenai pemangku kepentingan atau stakeholder dapat diartikan sebagai individu atau kelompok yang bisa memengaruhi dan/atau dipengaruhi oleh organisasi sebagai dampak dari aktivitas-aktivitasnya (Miles \& Friedman, 2006: 3). Dalam konteks penelitian ini, masyarakat sekitar RPTRA dan Satuan Kerja Perangkat Daerah (SKPD) setempat yang terkait dapat dikatakan sebagai pihak pemangku kepentingan yang memiliki peranan besar dan saling bersinergi satu sama lain untuk terutama untuk mendukung dan memaksimalkan pengelolaan di RPTRA Kalijodo. Hal tersebut dapat digambarkan pada skema 2.

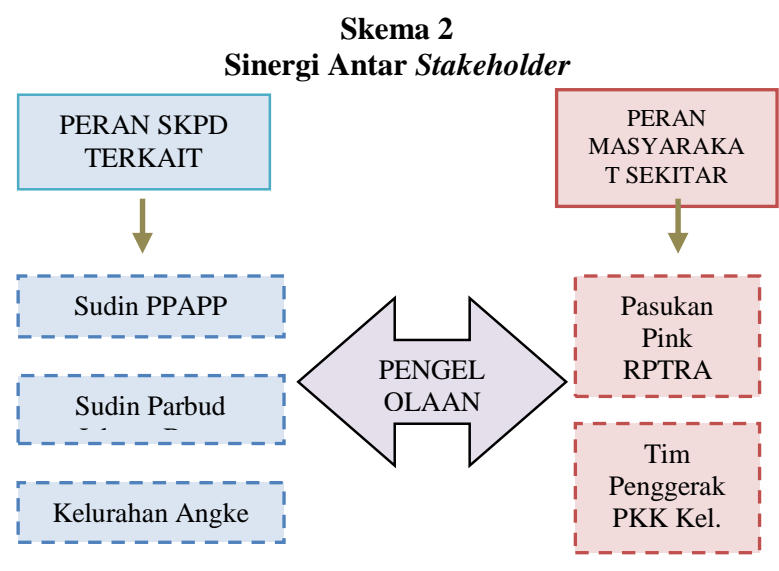

Sumber: Diolah oleh Peneliti (2018)

Berdasarkan skema tersebut dapat dijelaskan bahwa RPTRA Kalijodo merupakan suatu kebijakan yang diimplementasikan oleh beberapa pihak yang saling berelasi dan terkait satu sama lain dalam hal pelaksanaan dan pengelolaannya. Masing-masing stakeholder yang terlibat ini merupakan aktor-aktor kunci yang berperan secara langsung dalam pengelolan RPTRA Kalijodo. Pihak pemangku kepentingan yaitu SKPD setempat yang terkait dan masyarakat sekitar RPTRA berperan secara langsung dengan memanfaatkan kapasitas yang mereka miliki untuk mendukung jalannya pengelolaan dan pengawasan di RPTRA Kalijodo. Stakeholder yang terlibat ini sama-sama memiliki tujuan untuk mengelola dan mengawasi RPTRA agar kegiatan yang berlangsung di dalamnya dapat berjalan sesuai dengan fungsi yang seharusnya. Salah satu SKPD di tempat berdirinya RPTRA Kalijodo yang berperan sebagai sektor kunci dari program RPTRA ini adalah Suku Dinas PPAPP Jakarta Barat berperan dalam hal mendampingi dan mengawasi pengelolaan RPTRA di wilayah Jakarta Barat, salah satunya termasuk RPTRA Kalijodo. Selain Suku Dinas PPAPP Jakarta Barat, SKPD terkait lainnya yang berperan sebagai stakeholder adalah Suku Dinas Pariwisata dan Kebudayaan Jakarta Barat dan SKPD Kelurahan tempat berdirinya RPTRA Kalijodo yaitu Kelurahan Angke.

Suku Dinas Pariwisata dan Kebudayaan Jakarta Barat berperan dalam memfasilitasi penyelenggaraan kegiatan pelatihan seni budaya yang diadakan di masing-masing RPTRA yang terletak di wilayah Jakarta Barat salah satunya RPTRA Kalijodo. SKPD dari Kelurahan Angke melalui Lurah juga berperan dalam melakukan pengawasan dan evaluasi terhadap pelaksanaan kegiatan yang diselenggarakan di RPTRA Kalijodo. Mekanisme pengawasan yang dimulai dari kelurahan ini adalah dengan mengawasai kegiatan-kegiatan yang dilakukan di RPTRA Kalijodo, dari mulai direncanakan hingga berjalannya kegiatan-kegiatan tersebut.

Dalam konteks penelitian ini, SKPD yang terkait menjadi stakeholder yang memiliki kapasitas dalam mengawasi mekanisme pengelolaan di RPTRA Kalijodo. Selain sebagai unsur pengawas, SKPD sebagai pihak pemangku kepentingan yang terlibat ini dengan kemampuan yang dimilikinya juga berperan dalam merancang kegiatan-kegiatan masyarakat yang perlu ada di RPTRA Kalijodo. Hal tersebut tentunya turut menjadi faktor yang menentukan keberhasilan dari program RPTRA. Selain peran yang dilakukan oleh SKPD setempat 
yang terkait, tentunya diperlukan juga partisipasi aktif peran serta dari masyarakat sekitar agar pengelolaan RPTRA Kalijodo dapat berjalan dengan baik dan berkesinambungan.

Partisipasi masyarakat yang aktif menjadi suatu batas baru dalam hubungan antara pemerintah dan masyarakat. Pemerintah yang melibatkan masyarakat melalui partisipasi aktif dapat menjadi suatu cara dalam penguatan hubungan antara pemerintah dan masyarakat (Friedrich, 2001:48). Di RPTRA Kalijodo, peneliti melihat bahwa adanya keterlibatan dari sebagian masyarakat sekitar Kelurahan Angke sebagai stakeholder yang turut berperan dalam mengelola RPTRA Kalijodo. Dalam konsepnya, pemangku kepentingan dapat berupa organisasi, komunitas, kelompok sosial ekonomi, pemerintah, atau lembaga yang berasal dari berbagai dimensi pada setiap tingkat golongan masyarakat yang masing-masing memiliki potensi, sumber daya, serta terlibat dalam suatu aktivitas yang disesuaikan dengan kapasitas yang dimiliki (Kusumantantya,2013:35). Sebagian masyarakat sekitar RPTRA Kalijodo yang terlibat tentunya dapat dikatakan juga sebagai stakeholder karena dengan kapasitas yang mereka miliki, mereka dapat berkontribusi dan menjalankan perannya masingmasing dalam mengelola RPTRA Kalijodo.

Dalam penelitian ini, pihak pemangku kepentingan dari unsur masyarakat sekitar yang terlibat dalam mengelola RPTRA Kalijodo tergabung dalam Pasukan Pink yang berjumlah enam orang dimana masing-masingnya merupakan masyarakat sekitar Kelurahan Angke. Selain Pasukan Pink, Tim Penggerak PKK Kelurahan Angke pun menjadi stakeholder yang berperan dalam memaksimalkan jalannya kegiatan dan pengelolaan di RPTRA Kalijodo. Pasukan Pink di RPTRA Kalijodo menjadi stakeholder yang berperan dalam hal pelaksanaan dan pengelolaan RPTRA Kalijodo dengan menjaga dan merawat RPTRA serta melayani masyarakat yang datang ke RPTRA Kalijodo.

Selain itu, Tim Penggerak PKK di Kelurahan Angke juga berperan sebagai stakeholder yang terlibat dalam pengelolaan RPTRA Kalijodo dengan menjalankan program-program dan kegiatan PKK di dalam RPTRA. Program dan kegiatan yang dijalankan oleh Tim Penggerak PKK Kelurahan Angke di RPTRA Kalijodo diantaranya adalah kegiatan Gebyar Posyandu dan kegiatan wirausaha melalui sarana PKK Grossmart di RPTRA Kalijodo. Dalam pengelolaan RPTRA Kalijodo, peneliti menemukan bahwa adanya relasi berupa peran yang dilakukan oleh stakeholder yaitu SKPD setempat yang terkait dan masyarakat sekitar RPTRA yang saling bersinergi satu sama lain dalam mengelola RPTRA Kalijodo. Kerjasama dan sinergi ini memperlihatkan bahwa pada dasarnya pemerintah dapat menggandeng dan melibatkan masyarakat dalam pelaksanaan programnya yaitu RPTRA. Adanya komitmen dan kolaborasi antar stakeholder ini tentunya dapat menjadi salah satu pendorong agar RPTRA Kalijodo yang telah ada dapat terkelola sehingga kegiatan-kegiatan yang berlangsung didalamnya dapat dimanfaatkan oleh masyarakat dan menjadi suatu upaya dalam rangka pemenuhan hak dan kebutuhan anak.

\section{Kemitraan Intersektoral}

RPTRA Kalijodo dibangun sebagai suatu sarana untuk mewujudkan program Kota Layak Anak (KLA). Untuk mewujudkan program tersebut, tentunya dibutuhkan komitmen dan peran dari pihak pemangku kepentingan yang saling bersinergi dan terkoordinir secara menyeluruh. Pemangku kepentingan dapat berperan sebagai aktor (yang dapat diartikan sebagai individu, kelompok, 
organisasi) yang dapat bekerjasama dan mampu mengambil keputusan dan bertindak dengan cara yang terkoordinasi. Pemangku kepentingan juga dapat berperan sebagai pelaku sosial (social agent) yang terlibat dalam suatu tingkah laku yang mengandung tujuan dengan memanfaatkan sumbersumber daya yang mereka ketahui (Burns, 1987: 4).

Dalam konteks penelitian ini, dengan adanya peran yang dilakukan dan dengan kapasitas yang dimiliki oleh stakeholder yang terlibat melalui pemerintah setempat dan masyarakat sekitar, maka RPTRA yang ada di Jakarta khususnya RPTRA Kalijodo dapat terkelola dengan lebih optimal sehingga program dan kegiatan yang berlangsung didalamnya dapat menjadi salah satu pendorong untuk menjamin terpenuhinya hak dan perlindungan anak. Pemangku kepentingan pembangunan pada umumnya terdiri dari tiga aktor sebagaimana yang dikemukakan oleh John Martinussen, yaitu: state (negara) atau dalam konteks penelitian ini melalui pihak pemerintah, market/private sector (dunia bisnis/swasta) dan society (masyarakat) (Martinussen, 1999:291). Sejalan dengan Martinussen, Bitzer (2012) menyebut ketiga actor tersebut sebagai kemitraan intersektoral (intersectoral partnership). Ketiga sektor pada dasarnya memiliki peran yang tentunya berbeda antara satu dengan lainnya. Sama halnya apabila dikaitkan dengan konteks pengelolaan di RPTRA Kalijodo ini.

Stakeholder dari pihak pemerintah berperan dalam merancang dan membentuk kegiatan-kegiatan yang berlangsung di RPTRA serta mengawasi jalannya pengelolaan di RPTRA, khususnya di RPTRA Kalijodo. Sementara itu, stakeholder dari pihak private sector atau dunia bisnis cenderung berperan pada tahapan awal melalui kerja sama dengan pemerintah untuk membangun RPTRA
Kalijodo melalui program CSR. Sedangkan masyarakat sekitar bersama dengan pemerintah setempat yang terkait terlibat dalam pengelolaan yang berlangsung di RPTRA Kalijodo pasca RPTRA tersebut dibangun.

Crosby dalam Stakeholder Analysis: A Vital Tool for Strategic Managers menjelaskan bahwa pemangku kepentingan dapat diklasifikasikan menjadi tiga kelompok yaitu: kelompok pemangku kepentingan utama, kelompok pemangku kepentingan kunci, dan kelompok pemangku kepentingan penunjang (Crosby, 1992: 5). Pemangku kepentingan utama merupakan pemangku kepentingan yang menerima dampak positif dan negatif dari suatu kegiatan. Pemangku kepentingan penunjang merupakan perantara yang membantu proses penyampaian kegiatan. Sedangkan pemangku kepentingan kunci mempunyai pengaruh yang penting dan kuat terkait dengan masalah, kebutuhan, dan perhatian terhadap kelancaran kegiatan. Untuk mencermati mengenai klasifikasi stakeholder yang terlibat di RPTRA Kalijodo, peneliti akan menampilkannya dalam tabel 3 .

Tabel 3

Klasifikasi Stakeholder dalam Pengelolaan RPTRA Kalijodo

\begin{tabular}{|l|l|l|}
\hline $\begin{array}{l}\text { Stakeholder } \\
\text { Penunjang }\end{array}$ & $\begin{array}{l}\text { Stakeholder } \\
\text { Kunci }\end{array}$ & $\begin{array}{l}\text { Stakeholder } \\
\text { Utama }\end{array}$ \\
\hline & $\bullet$ Pemerintah & \\
& Setempat \\
& Terkait: & • Masyarakat \\
& Sekitar: \\
Swasta: & Suku Dinas & $\bullet$ Pasukan \\
Melalui & PPAPP Jakarta & Pink \\
program & Barat; & RPTRA \\
CSR & Suku Dinas & Kalijodo; \\
Sinarmas & Pariwisata \& & dan \\
Land, & Kebudayaan & Tim \\
Tbk. & Jakarta Barat; & Penggerak \\
& dan & PKK \\
& Kelurahan & Kelurahan \\
& Angke, Jakarta & Angke. \\
& Barat. & \\
\hline
\end{tabular}

Tabel 3 menjelaskan bahwa pihak swasta termasuk dalam stakeholder penunjang karena 
menjadi pihak perantara dalam menunjang program KLA. Selain pemerintah dan masyarakat, keterlibatan pihak swasta memang diperlukan untuk mewujudkan program KLA yang mana dalam konteks penelitian ini hal tersebut dibuktikan dengan adanya kontribusi dari perusahaan Sinarmas Land dalam mendanai pembangunan RPTRA Kalijodo melalui program CSR. Akan tetapi keterlibatan dari pihak swasta dalam hal ini hanya terjalin pada tahapan awal saja yaitu pada tahap proses pembangunan. Sementara itu, pemerintah setempat yang terkait peneliti klasifikasikan menjadi stakeholder kunci karena tentunya pemerintah memiliki pengaruh yang penting dan kuat terkait dengan masalah, kebutuhan, dan perhatian terhadap program RPTRA ini. Sedangkan masyarakat sekitar RPTRA Kalijodo dapat diklasifikasikan sebagai stakeholder utama karena selain masyarakat sekitar yang nantinya akan menerima manfaat dari keberadaan RPTRA Kalijodo, masyarakat sekitar juga yang pada akhirnya berperan dan dilibatkan oleh pemerintah dalam mengelola RPTRA tersebut.

Berdasarkan penjelasan tersebut, dapat diidentifikasi bahwa pihak pemangku kepentingan yang terlibat terutama stakeholder utama dan stakeholder kunci saling bekerjasama dalam pengelolaan RPTRA Kalijodo. Dalam prosesnya, stakeholder tersebut memegang peranannya masingmasing dan saling berkontribusi dalam upaya keberhasilan jalannya pengelolaan di RPTRA Kalijodo. Peran yang dilakukan oleh stakeholder tentunya diperlukan agar RPTRA Kalijodo dapat terkelola secara maksimal. Adapun analisis mengenai peran stakeholder dalam mengelola RPTRA Kalijodo dapat dijelaskan dalam tabel 4.

Tabel 4

Klasifikasi dan Peran Stakeholder

\begin{tabular}{|c|c|c|c|c|}
\hline No. & \multicolumn{2}{|c|}{ Klasifikasi Stakeholder } & Peran Stakeholder & Kegiatan Terkait Peran \\
\hline \multirow{3}{*}{1.} & \multirow{3}{*}{$\begin{array}{l}\text { Stakeholder } \\
\text { Kunci }\end{array}$} & $\begin{array}{l}\text { Suku Dinas PPAPP } \\
\text { Jakarta Barat }\end{array}$ & $\begin{array}{l}\text { Mengawasi pengelolaan } \\
\& \text { perancang program }\end{array}$ & $\begin{array}{l}\text { - Mengawasi jalannya mekanisme pengelolaan } \\
\text { di RPTRA Kalijodo; } \\
\text { - Menyeleksi Pasukan Pink } \\
\text { - Merancang program dan kegiatan program } \\
\text { yang perlu ada dalam suatu RPTRA. }\end{array}$ \\
\hline & & $\begin{array}{c}\text { Suku Dinas Pariwisata } \\
\text { dan Kebudayaan Jakarta } \\
\text { Barat } \\
\end{array}$ & $\begin{array}{c}\text { Ket.: Analisis Peneliti (2018) } \\
\text { Perancang program }\end{array}$ & $\begin{array}{l}\text { - } \begin{array}{l}\text { Merancang program dan kegiatan yang perlu } \\
\text { ada dalam suatu RPTRA, khususnya } \\
\text { program di bidang seni budaya. }\end{array} \\
\end{array}$ \\
\hline & & $\begin{array}{l}\text { Kelurahan Angke } \\
\text { Jakarta Barat }\end{array}$ & Mengawasi pengelolaan & $\begin{array}{l}\text { - Mengawasi jalannya mekanisme pengelolaan } \\
\text { dan kegiatan yang berlangsung di RPTRA } \\
\text { Kalijodo; } \\
\text { - Menggerakkan unsur dari kelurahan (misal: } \\
\text { PKK) sebagai pelaksana program di dalam } \\
\text { RPTRA Kalijodo. }\end{array}$ \\
\hline \multirow[t]{2}{*}{2.} & \multirow{2}{*}{$\begin{array}{l}\text { Stakeholder } \\
\text { Utama }\end{array}$} & $\begin{array}{c}\text { Pasukan Pink RPTRA } \\
\text { Kalijodo }\end{array}$ & $\begin{array}{l}\text { Pelaksana program dan } \\
\text { kegiatan }\end{array}$ & $\begin{array}{l}\text { - Sebagai fasilitator bagi kegiatan-kegiatan } \\
\text { masyarakat yang diselenggarakan di } \\
\text { RPTRA Kalijodo. }\end{array}$ \\
\hline & & $\begin{array}{l}\text { TP. PKK Kelurahan } \\
\text { Angke } \\
\end{array}$ & $\begin{array}{l}\text { Pelaksana program dan } \\
\text { kegiatan }\end{array}$ & $\begin{array}{ll}\text { - } & \text { Pelaksana kegiatan-kegiatan dan program- } \\
\text { program PKK di RPTRA Kalijodo. }\end{array}$ \\
\hline 3. & $\begin{array}{l}\text { Stakeholder } \\
\text { Penunjang }\end{array}$ & Sinarmas Land, Tbk. & $\begin{array}{c}\text { Kontribusi dalam proses } \\
\text { pembangunan RPTRA } \\
\text { Kalijodo } \\
\end{array}$ & $\begin{array}{l}\text { Terlibat dalam mendanai proses } \\
\text { pembangunan RPTRA Kalijodo dalam } \\
\text { tahapan awal melalui program CSR. }\end{array}$ \\
\hline
\end{tabular}

\section{E. Peran Pemangku Kepentingan: Antara Krisis Ruang Publik ke Kasadaran Warga}

Keterlibatan dan peran yang dilakukan oleh stakeholder seperti yang nampak pada tabel 4 menjadi suatu kemitraan antara pemerintah setempat 
yang terkait dan masyarakat sekitar dalam pengelolan RPTRA Kalijodo. Kemitraan memang dapat dilatarbelakangi oleh kesadaran pemerintah akan keterbatasannya dalam menyediakan pelayanan publik dan mengatasi masalah sosial. Melalui kemitraan ini diharapkan akan adanya peran serta dari aktor masyarakat dan swasta yang membantu upaya pembangunan yang dilakukan oleh pemerintah (Bappenas, 2011: 16).

Kemitraan yang terjalin dengan masyarakat sekitar dalam pengelolaan RPTRA Kalijodo pada akhirnya juga dapat memberikan kemudahan bagi pemerintah setempat dalam menjalankan kebijakannya khususnya dalam program RPTRA. RPTRA Kalijodo yang terkelola ini pada akhirnya dapat menjadi suatu ruang dengan berbagai kegiatan masyarakat yang dihidupkan didalamnya. Dengan berlangsungnya beragam kegiatan yang ada, RPTRA Kalijodo tentunya menjadi sarana yang dapat dimanfaatkan keberadaannya oleh masyarakat. Selain itu, adanya RPTRA ini tentunya juga dapat menjadi arena titik temu antara pemerintah, swasta, dan masyarakat dalam menciptakan sarana dan wadah berkumpul bagi masyarakat khususnya anakanak untuk melakukan berbagai kegitan dan aktivitas sosial di ruang publik. Saat ini dengan adanya RPTRA Kalijodo masyarakat khususnya anak-anak disekitar RPTRA tersebut dapat lebih mudah untuk mengakses kebutuhan akan ruang publik yang aman dan nyaman bagi mereka. Di samping itu, pembangunan RPTRA salah satunya juga memiliki fungsi yang strategis untuk menjaga keseimbangan kehidupan masyarakat perkotaan terutama dalam aspek kehidupan sosial terkait dengan ruang interaksi dan sosialisasi masyarakat akar rumput perkotaan. Kehadiran RPTRA tidak semata sebagai sarana penunjang tata ruang kota, namun juga telah menjadi salah satu ruang untuk memenuhi kebutuhan masyarakat. Dengan adanya RPTRA, masyarakat dapat merasakan hadirnya ruang publik ditengahtengah mereka sebagai tempat untuk saling berinteraksi dan berkegiatan di dalamnya.

\section{Kesimpulan}

Berdasarkan penjelasan di atas, dapat disimpulkan beberapa hal. Pertama, kemitraan pemangku kepentingan yang ada dalam pengelolaan RPTRA menunjukkan bahwa pemerintah bukan satusatunya pemangku kepentingan yang dominan dalam program pembangunan kota. Tetapi ada beberapa pemangku kepentingan yang peran dan kontribusinya. Keberadaan berbagai pemangku kepentingan tersebut berlangsung dalam satu relasi dan kolaborasi satu dengan lainnya. Menurut Wilkinson,et.al (2014), kolaborasi dan kemitraan memiliki keterkaitan masing-masing studi-studi mengenai fenomena organisasi dan politik. Kedua, latar belakang adanya kemitraaan pemangku kepentingan dalam kegiatan RPTRA sejalan dengan konsep pembangunan kota berkelanjutan yang didasari oleh munculnya masalah sosial di perkotaan yaitu krisis ruang publik yang mendegradasikan kehidupan sosial masyarakat kota. Kemitraan ini menjadi pintu masuk dalam membangun jembatan dan ruang terjadinya transfer dan pertukaran kapasitas kolektif di antara berbagai pemangku kepentingan. Oleh karena itu, kemitraan ini tidak semata-mata dipahami dalam kepentingan jangka pendek tetapi dalam konteks membangun kota yang humanis dan sinergis di antara warga masyarakatnya.

\section{Daftar Pustaka}

Ackermann, Fran and Eden, Colin. (2010). Strategic Management of Stakeholders: Theory and Practice. Long Range Planning 44 (2011) pp. 179-196. 
BAPPENAS. (2011). PPP Policy and Regulation in Indonesia. Jakarta: PKPS.

Bitzer, Verena (2012). Partnering for Change in Chains: the Capacity of Partnerships to Promote Sustainable Change in Global Agrifood Chains. International Food and Agribusiness Management Review Volume 15, Special Issue B, 2012, pp. 13-38.

Burns, Tom R, dkk. (1987). Manusia, Keputusan, Masyarakat (Teori Dinamika Antara Aktor dan Sistem Untuk Ilmuwan Sosial). Penerjemah: Soeswono Hadisoenarto. Jakarta: PT Pradnya Paramita.

Cavin, Susan (2005).Imaginary Social Relations. Presented at the July 2005 International Sociological Associations Meetings in Stockholm, Sweden, 5-9 July 2005.

Crosby, B.L. (1992). Stakeholder Analysis: A Vital Tool for Strategic Managers. Technical Notes, No. 2. Agency for International Development. Washington DC.

Friedrich, Nauman. (2001). Citizens as Partners (Warga Negara sebagai Mitra. Organisation for Economic Co-Operation and Development.

Kusumatantya, Irene (2013). Peran Pemangku Kepentingan dalam Pembentukan Komunitas Guna Mencapai Ketahanan Sosial Ekonomi Masyarakat. Jurnal Wilayah dan Lingkungan, Vol. 1 No. 1 April 2013.

Martinussen, John. 1999. Society, State, and Market: A Guide to Completing Theories of Development.London and New York: Hlmifax, Nova Scotia.

MacDonald, Adriane (2016). Multi-Stakeholder Partnerships for Community Sustainability Plan Implementation: Understanding Structures and Outcomes at the Partner and Partnership Levels. A thesis presented to the University of Waterloo in fulfilment of the thesis requirement for the degree of Doctor of Philosophy in Social and Ecological Sustainability. Waterloo, Ontario, Canada

Miles, Samantha \& Friedman, Andrew Lloyd (2006). Stakeholders: Theory and Practices. Oxford University Press: UK.

Nauman, Friedrich (2001). Citizens as Partners (Warga Negara sebagai Mitra. Organisation for Economic Co-Operation and Development.

Neuman, W. Lawrence. (2015). Metodologi Penelitian Sosial: Pendekatan Kualitatif dan Kuantitatif (Edisi 7). Penerjemah: Edina T. Sofia. Jakarta: PT Indeks.

Rencana Pembangunan Jangka Menengah Daerah (RPJMD) Provinsi Daerah Khusus Ibu kota
Jakarta Tahun 2013-2017. Badan Perencanaan Pembangunan Daerah Provinsi DKI Jakarta.

Rosalin, Lenny. Bahan Advokasi Kebijakan KLA. Deputi Bidang Tumbuh Kembang Anak, Kementerian Pemberdayaan Perempuan dan Perlindungan Anak Republik Indonesia.

Sulistyani, Ambar Teguh. (2004). Kemitraan dan Model-Model Pemberdayaan. Yogyakarta: Penerbit Gaya Media.

Katalog BPS Provinsi DKI Jakarta Tahun 2017. http://jakarta.bps.go.id. Diakses pada 24 Februari 2018 pukul 10.15 WIB.

Keputusan Menteri Negara Pemberdayaan Perempuan dan Perlindungan Anak Republik Indonesia No. 56 Tahun 2010 tentang Penunjukan dan Penetapan 10 Kabupaten/Kota Layak Anak. http://jdih.kemenpppa.go.id. Diakses pada 4 April 2018 pukul 14.27 WIB.

Peraturan Gubernur Provinsi DKI Jakarta No. 40 Tahun 2016. http://jakarta.go.id. Diakses pada $8 \quad$ Februari 2018 pukul 11.31 WIB.

Wilkinson, Adrian, Tony Dundon, Jimmy Donaghey \& Keith Townsend (2014). Partnership, Collaboration And Mutual Gains: Evaluating Context, Interests And Legitimacy. The International Journal of Human Resource Management, 25:6, 737-

747, DOI: $\underline{10.1080 / 09585192.2014 .868713}$ 